\title{
Palabras del señor Presidente de la República, doctor Ernesto Samper Pizano
}

Un cumpleaños institucional es siempre motivo de orgullo, máxime si se trata, como en esta ocasión, de un centro de investigación científica para mejorar la salud pública.

Nos reune en esta mañana, la celebración de ocho décadas de trabajo continuo del Instituto Nacional de Salud, que nació como un laboratorio, auspiciado por dos médicos quijotes, los doctores Bernardo Samper Sordo y Jorge Martínez Santamaría. Digo quijotes, porque se trataba de dos médicos enamorados de su profesión, con enorme sensibilidad social, dispuestos a servir a su comunidad entregando al servicio de esta causa no sólo su patrimonio científico, sino su fortuna y hasta su propia vida como fue el caso del doctor Martínez que murió de difteria, probablemente contraida durante su trabajo en el laboratorio. Y cumplieron con sus propósitos y es por ello que hoy les tributamos un homenaje de cariño y admiración; de manera personal, recuerdo a mi pariente, el doctor Bernardo Samper, que siempre fue nombrado en mi casa y puesto de ejemplo como un personaje solidario y brillante.

En esa época, 1917, nuestro país era otro país. Un país rural, atrasado, plagado de enfermedades y carente de una política sanitaria y epidemiológica.

El país cambió, mejoró y avanzó, y de manera paralela lo ha hecho esta institución. En 1927, el Estado lo compró y se convirtió en el Laboratorio Nacional de Higiene Samper Martínez, nombre que da buena cuenta de la situación primitiva que se vivía y del grado de desarrollo de la ciencia y de la tecnología en salud. La higiene era, para ese entonces, sinónimo por excelencia de salud.

Muchos han sido los retos alcanzados y muchos los obstáculos vencidos por el Instituto Nacional de Salud, nombre que lleva hace ya 20 años. Me haría interminable señalando los hitos de su historia, que han ido de la mano con el desarrollo científico del país. Lo que no quiero dejar de destacar es el aporte de tantos hombres y mujeres que han trabajado en este Instituto en beneficio de la salud de los habitantes de este país, dedicando lo mejor de su saber para ganarle la guerra a la enfermedad, sobre todo a la producida por patologías virales y endémicas que son las que atacan con más furia y diezman mayor población.

Pero, no se ha quedado el trabajo del Instituto solamente en la investigación para la producción de biológicos, sino que se ha dedicado con regularidad a otro frente importante de la ciencia: el de las publicaciones. Se han producido tres estudios nacionales sobre salud, biblia para legos y profanos, en donde se hace una acertada radiografía de la salud pública en Colombia. Así mismo, durante los últimos 17 años, se ha editado de manera permanente la revista Biomédica, punto de referencia obligado a nivel nacional y de consulta internacional y el Informe Quincenal Epidemiológico Nacional, que se realiza conjuntamente con el Ministerio de Salud.

Una de las más importantes realizaciones del Instituto fue la producción, el año pasado, de 14 millones de dosis de vacunas infantiles, con lo cual se dio cumplimiento a la meta de vacunación que se fijó el Ministerio de Salud.

En los últimos años, el Instituto ha dispuesto que un grupo importante de sus científicos se dediquen al estudio de enfermedades como el cáncer de seno y el SIDA y su relación con la tuberculosis.

No podía esta institución sustraerse al impacto de la violencia social y, por ello, vienen adelantando 
estudios sobre ese cáncer que afecta nuestra sociedad desarroliando investigaciones sobre violencia intrafamiliar y violencia a nivel general.

Hoy tiene el Instituto como su director, al químico de la Universidad Nacional, Moisés Wasserman Lerner, Ph.D. en bioquímica de la Universidad de Jerusalén y postdoctorante de microbiología en la Universidad de Nueva York. El doctor Wasserman ha sido reconocido con el Premio Nacional de Ciencias por la Fundación Alejandro Angel Escobar y como Docente Excepcional y Profesor Emérito de la Universidad Nacional. Estos reconocimientos dan buena cuenta de un hombre dedicado a la ciencia y a la enseñanza, que emula, con sobrados atributos, esos dos colegas que hace ochenta años, de manera visionaria, idearon este centro de ciencia.

El doctor Wasserman repite que "la ciencia, cada día más, además de ser hecha debe ser defendida", postulado que comparto y como Primer Mandatario de la Nación deseo que se practique en espacios como éste del Instituto Nacional de Salud, en donde es necesario defender ese patrimonio científico construido de manera colectiva, con la suma de saberes de hombres y mujeres que dedican su conocimiento y trabajo para controlar la enfermedad y evitar la muerte.

Científicos como químicos, biólogos, microbiólogos, bacteriólogos, farmaceutas, médicos y veterinarios, unos para optar a su título de pregrado, otros a los de magister y otros al doctorado, han colocado su granito de arena en este Instituto para engrandecer nuestra ciencia. Ciencia que es a la vez patrimonio de la humanidad, ya que todo avance científico se socializa.

Colombia avanza en el campo científico. La legislación acompaña este avance, sin duda, no de la manera como lo esperaría la comunidad científica, pero de todos modos tanto el Ejecutivo como el Legislativo intentan cumplir con su papel de auxiliadores efectivos de la brega científica. En virtud de este compromiso, la Ley 100 creó el INVIMA como espacio técnico para asumir responsabilidades que venía cumpliendo el Instituto. Estas dos instituciones son los soportes del Gobierno para trazar la política en salud pública.

Es claro que nos falta camino por recorrer en la investigación biomédica y sobre todo en ese campo de la salud sicosocial en que nos hemos sumergido por cuenta de unos violentos dementes que siembran terror y muerte desde orillas diversas, pero sobre el mismo espacio geográfico.

Esta dramática situación convierte este cumpleaños ochenta no en la celebración de un ente viejo que goza de buena salud sino en el de una institución con mucho reto por cumplir, joven y briosa, de la cual los colombianos esperamos muchos frutos para el bienestar nacional.

Mi felicitación a todos los funcionarios del Instituto y mis deseos para que, como lo expiesa el doctor Wasserman, la construcción nacional desde diversos espacios nos lleve a posicionarnos como una nación rica en ciencia y saber, únicas llaves que nos permitirán abrir!e la puerta al desarrollo social con equidad que, desde hace tantas décadas, venimos buscanco.

Búsqueda que no es fácil ni gratuita, como la mavoría quisiera. Vale la pena para terminar, citar ante ustedes, infatigables trabajadores de la ciencia, al maestro Estanislao Zuleta cuando decía que: "En lugar de desear una relación humana inquietante, compleja y perdible, que estimule nuestra capacidad de luchar y nos obiigue a cambiar, deseamos un idilio sin sombra y sin peligros, un nido de amor y, por lo tanto, en última instancia, un retorno al huevo.

En lugar de desear una sociedad en la que sea necesario trabajar arduamente por hacer efectivas nuestras posibilidades, deseamos un mundo de satisfacción, una monstruosa salacuna de abundancia pasivamente recibida. En lugar de desear unia filosofía llena de incógnitas y preguntas abiertas, queremos poseer una doctrina global, capaz de dar cuenta de todo, revelada por espíritus que nunca han existido o por caudillos que desgraciadamente sí han existido."

Aquí, en el Instituto Nacional de Salud, se ha demostrado y se seguirá demostrando que se desea 
bien. Su deseo permanente es por encontrar salidas científicas a los problemas de la salud y el bienestar. Recuerdo todos los días los esfuerzos de muchos de sus investigadores cuando estuve en peligro de muerte y acá se logró aislar la infección que padecía. De no ser por su dedicación y certeza, hoy no estaría con ustedes. Dice el doctor Wasserman que del Instituto poco se oye hablar, puede que tenga razón, pero como mi caso hay muchos otros de colombianos que le debemos la vida al Instituto y este agradecimiento es más importante para cualquier institución que aparecer en primera página todos los días.

Mil gracias.

Santa Fe de Bogotá, 14 de marzo de 1997 